\title{
La exclusión de la participación de las Organizaciones Sindicales en los órganos de selección de las Administraciones Públicas, por exigencia del Estatuto Básico del Empleado Público
}

\author{
Jorge Fondevila Antolín \\ Jefe de la Asesoría Jurídica de la Consejería de Presidencia \\ y Justicia del Gobierno de Cantabria \\ Secretario de Administración Local
}

\begin{abstract}
Sumario: I. INTRODUCCIÓN: LA GÉNESIS DE LA EXCLUSIÓN. - II. EXAMEN DE LOS FUNDAMENTOS JURÍDICO CONSTITUCIONALES QUE AMPARAN LAS PREVISIONES DE EXCLUSIÓN RECONOCIDAS EN EL ARTÍCULO 60.3 EBEP. A) El acceso al empleo público como derecho de los ciudadanos. B) Las Consecuencias de la aplicación de los Principios de Imparcialidad, Profesionalidad e Independencia en la composición de los órganos de selección (art. 55.2 EBEP).-III. EXAMEN DEL DERECHO DE LIBERTAD SINDICAL: ¿HAY COLISIÓN ENTRE ESTE DERECHO Y LA DECISIÓN LEGAL DE EXCLUSIÓN DE LAS ORGANIZACIONES SINDICALES, ASOCIACIONES PROFESIONALES Y DEMÁS ÓRGANOS DE REPRESENTACIÓN DE LOS ÓRGANOS DE SELECCIÓN? A) Análisis de la configuración del Derecho de Libertad Sindical en el orden constitucional español B) Examen del régimen de participación de los órganos unitarios de representación del Personal al servicio de las Administraciones Públicas (Juntas de Personal y Comités de Empresa). - IV. EXAMEN DEL ARTÍCULO 60.3 DEL EBEP, EN CONCRETO, SU PREVISIÓN DE EXCLUSIÓN DE LAS ORGANIZACIONES SINDICALES, ASOCIACIONES PROFESIONALES Y DEMÁS ÓRGANOS DE REPRESENTACIÓN DE LOS ÓRGANOS DE SELECCIÓN. - V. CONSIDERACIONES FINALES.
\end{abstract}

\section{INTRODUCCIÓN: LA GÉNESIS DE LA EXCLUSIÓN}

Estamos en presencia de una de las más llamativas novedades introducidas por la Ley 7/2007 EBEP, en concreto, la exclusión de las organizaciones sindicales de su participación en los órganos de selección en las administraciones públicas, tal como determina el artículo 60.3 del EBEP.

Pues bien, esta cuestión ya fue abordada en los trabajos preparatorios del Proyecto de Ley del EBEP, en concreto, por la Comisión de Expertos convocada al efecto ${ }^{1}$, siendo necesario, a nuestro juicio, destacar algunas de las consideraciones formuladas por la misma, así, señala:

\footnotetext{
1 Nos referimos al denominado «Informe de la Comisión para el Estudio y Preparación del Estatuto Básico del Empleado Público», INAP - Madrid - 2005, págs. 91 y ss. , elaborado por encargo del MAP.
} 
Ningún sistema de selección puede ser fiable, sino se garantiza en sus órganos de selección la exigencia de los principios de imparcialidad, objetividad y profesionalidad.

Los órganos de selección deben quedar al margen de cualquier influencia partidaria, gremial, sindical o corporativa.

Considera la Comisión como práctica inadmisible para un funcionamiento correcto del sistema de selección, ya que carece de justificación objetiva, el uso que se ha hecho en nuestro país de configurar la composición de los órganos de selección «mediante la designación de sus miembros por o en representación de grupos políticos o sindicales...».

Por último, se propone por la Comisión de forma expresa «la exclusión de ....representantes de los sindicatos, órganos unitarios de representación del personal o asociaciones que ejerzan funciones representativas de los empleados públicos».

Como consecuencia de estas propuestas, el primer borrador del anteproyecto que se elaboro por el MAP, con fecha 25 de noviembre de 2005, establecía expresamente la exclusión propuesta ${ }^{2}$ por la Comisión de expertos, el citado texto fue objeto de negociación con Comunidades Autónomas, Federación Española de Municipios y Provincias (FEMP) y organizaciones sindicales ${ }^{3}$ ( CC.OO, Csi-Csif y UGT), de manera que se elabora un segundo borrador, con fecha 17 de abril de 2006 que mantiene la misma redacción de la exclusión ${ }^{4}$, a este texto se le vuelven a realizar nuevas consideraciones continuando el proceso negociador con los mismos interlocutores, que en el caso sindical se concreta en la reunión celebrada el día 4 de mayo de 2006, en la cual vuelven a insistir estas organizaciones en exigir su presencia en los órganos de selección, tras la celebración de otras dos reuniones en fechas de 11 y 17 de mayo, no se alcanza un acuerdo a este respecto de forma que se mantuvo la redacción inicial en el Proyecto de Ley que se presento ante el Congreso de los Diputados ${ }^{5}$, ahora

2 Efectivamente el artículo 39.2 del Anteproyecto señalaba: «No podrán formar parte de los órganos de selección el personal de elección o designación política, ...... en representación de los sindicatos, órganos unitarios de representación del personal o asociaciones que ejerzan funciones de representación de los empleados públicos».

3 La primera de las reuniones celebradas entre las organizaciones sindicales y el MAP, se celebro el día 13 de febrero de 2006, continuando la negociación en las sesiones de los días 20 de febrero, 1, 8 y 15 de marzo, finalizando aquí una primera fase de negociación, que no pudo modificar la redacción del artículo que excluye a las mismas de los órganos de selección.

4 En concreto, el nuevo borrador incorpora esta previsión en el artículo 60.2.

5 En concreto, se publicó en BOCG. Congreso de los Diputados Núm. A-94-1 de 08/09/2006, el artículo 60, con el siguiente texto:

Órganos de selección.

1. Los órganos de selección serán colegiados y su composición deberá ajustarse a los principios de imparcialidad y profesionalidad de sus miembros, y se tenderá, asimismo, a la paridad entre mujer y hombre. 
bien, durante su tramitación parlamentaria, algunas organizaciones sindicales mantuvieron encuentros con los grupos políticos con la finalidad, entre otras cuestiones, de que se les reconociera el derecho a formar parte de los órganos de selección, petición que fue atendida de forma parcial por algún grupo parlamentario ${ }^{6}$, como consecuencia del debate suscitado por la presentación de estas enmiendas y la presión sindical, se alcanzo un acuerdo de consenso en el seno de la Comisión de Administraciones Públicas, así, el Dictamen ${ }^{7}$ de la misma modifico el texto inicial del Proyecto de Ley, de forma que la nueva redacción no menciona expresamente a las organizaciones sindicales, pero sin embargo si se mantiene la finalidad y estructura normativa del mismo, y como consecuencia de ello, aunque no aparezcan mencionadas expresamente, a nuestro juicio, y como acreditaremos posteriormente, estas continúan quedando excluidas de los órganos de selección.

Debemos llamar la atención también sobre las previsiones del artículo 31.6 del EBEP, que desde la redacción original del Proyecto de Ley admitido a trámite, señalaba expresamente lo siguiente:

6. Las Organizaciones Sindicales más representativas en el ámbito de la Función Pública están legitimadas para la interposición de recursos en vía administrativa y jurisdiccional contra las resoluciones de los órganos de selección.

Pues bien, este precepto no fue objeto de enmienda alguna y se mantuvo incólume hasta su aprobación definitiva, y su finalidad desde que fue incorporado

2. El personal de elección o de designación política y el personal eventual no podrá formar parte de los órganos de selección.

3. La pertenencia a los órganos de selección será siempre a título individual, no pudiendo ostentarse ésta en representación de asociaciones, organizaciones sindicales, órganos unitarios de representación del personal o cualquier otra entidad representativa de intereses.

6 Así, BOCG Congreso de los Diputados n. A - 94 - 9 de 24 de noviembre de 2006:

El Grupo Parlamentario de Izquierda Unida-Iniciativa per Catalunya Verds , formulo dos enmiendas n. ${ }^{\circ} 173$ (de supresión del apartado $3 .^{\circ}$ del artículo 60) y la n. ${ }^{\circ} 174$ de adicción que señalaba: Se propone añadir en el apartado 3 del artículo 60 el siguiente texto:

«Las organizaciones sindicales representativas, podrán participar con efectos fiscalizadores en los órganos de selección. Esta participación será con voz pero sin voto.»

Por otro lado, D. Francisco Rodríguez Sánchez (Grupo Parlamentario Mixto), presenta la enmienda n. ${ }^{\circ} 243$, de adicción de un nuevo apartado cuarto al artículo 60, que señala lo siguiente:

«4. Las organizaciones sindicales tendrán derecho a recibir información y a efectuar un seguimiento de los procesos de selección.»

Por último, el Grupo Parlamentario de Esquerra Republicana (ERC), presento la enmienda n. ${ }^{\circ} 299$, de supresión íntegra del apartado $3 .^{\circ}$ del citado artículo.

7 Así, por Dictamen de Comisión de fecha 15 de diciembre de 2006, que aprueba el texto que iba a ser objeto de examen y votación en el Pleno del Congreso, se modifico el apartado tercero del artículo 60, si bien, no en el sentido de ninguna de las enmiendas presentadas que fueron rechazadas todas ellas, sino mediante una fórmula de consenso, que no modificaba el sentido final del precepto (BOCG Congreso de los Diputados n. ${ }^{\circ}$ A-94-13 de 20 de diciembre de 2006. 
a los diferentes anteproyectos era única y exclusivamente «compensar»a las organizaciones sindicales por la pérdida de su cuota de poder, en el desarrollo de los procesos selectivos, al perder estos la facultad que tenían hasta ese momento reconocida legalmente para formar parte de los órganos de selección.

\section{EXAMEN DE LOS FUNDAMENTOS JURÍDICO CONSTITUCIONALES QUE AMPARAN LAS PREVISIONES DE EXCLUSIÓN RECONOCIDAS EN EL ARTÍCULO 60.3 EBEP}

\section{A) El acceso al empleo público como derecho de los ciudadanos}

Efectivamente, durante mucho tiempo se ha considerado que el acceso y la selección de los empleados públicos, formaban parte del orden «Estatutario», y por ello, los procedimientos de selección se encontraban controlados por los aparatos políticos y burocráticos, en algunos casos, pero esta consideración nunca ha sido ajustada del todo a nuestro orden constitucional, pues recordemos que el sentido de las previsiones, en especial, las del artículo 23.2, que señala: que los ciudadanos tienen «Derecho a acceder en condiciones de igualdad a las funciones y cargos públicos con los requisitos que señalen las Leyes» y también el artículo 103.3 de la CE. ${ }^{8}$, es considerar que estamos en presencia de un «derecho de los ciudadanos» al acceso al empleo público (STC 192/1991 y 138/2000, entre otras), que además goza de una especial protección de acuerdo con las previsiones del artículo 53.1 C.E., y este sentido, afortunadamente, ha sido recogido por el artículo 55.1 del EBEP, cuándo establece literalmente la siguiente previsión: «Todos los ciudadanos tienen derecho al acceso al empleo público...», y este cambio de orden de análisis de la cuestión condiciona necesariamente la línea interpretativa que debe guiar el examen de la nueva regulación establecida por el EBEP.

A este respecto, podemos destacar como se están produciendo innovaciones legislativas, en algunas normas integrantes del denominado «bloque de constitucionalidad» ${ }^{9}$, en concreto, nos referimos a las previsiones del vigente

\footnotetext{
8 Lorenzo De Membiela, J. B., (2005), «El Acceso y la Provisión de puestos de trabajo en la Administración Pública», Aranzadi-Pamplona, págs. 54 y ss., e igualmente PUERTA SEGUIDO, F., (2003), «La consolidación del Empleo Público Precario», Lex Nova-Valladolid, págs. 47 y ss., y por último, el gran trabajo de FERNÁNDEZ FARRERES, G. (1992), «Régimen Jurídico de la Función pública y Jurisprudencia Constitucional». Revista del Centro de Estudios Constitucionales, n. ${ }^{\circ} 12$, Centro de Estudios Constitucionales-Madrid, págs. 61 y ss.

9 Figura incorporada por la Doctrina de nuestro Tribunal Constitucional, en sus SsTC 66/1985, 11/1986, 26/1987, 154/1988 y 149/1991, entre otras, para un examen más detallado de la cuestión TOMAS Y VALIENTE, F (1985), en la obra «Tribunales Constitucionales Europeos y Autonomías Territoriales», VV.AA, Centro de Estudios Constitucionales, Madrid, págs. 175 y ss. y también, AGUAdo RENEDO, C. (1996) «El Estatuto de Autonomía y su posición en el Ordenamiento Jurídico», Centro de Estudios Constitucionales, Madrid, págs. 511 y ss.
} 
Estatuto de Autonomía de Andalucía que, reconoce en su artículo 136, la posibilidad de la elaboración de una Ley específica para el acceso al empleo público, diferente e independiente de la Ley de Función Pública para esa Administración, que lógicamente deberá desarrollar los contenidos del régimen «Estatutario de sus funcionarios y las correspondientes modulaciones del resto de sus empleados públicos». Este cambio legal y real sobre cual debe ser el sujeto destinatario del derecho legal al acceso al empleo público, es el que ha servido como fundamento axiológico constitucional para las modificaciones legales del EBEP, objeto de este trabajo, en concreto, la composición especializada, objetiva y sin ingerencias políticas ni sindicales de los órganos encargados de la selección.

\section{B) Las Consecuencias de la aplicación de los Principios de Imparcialidad, Profesionalidad e Independencia en la composición de los órganos de selección (art. 55.2 EBEP)}

De forma preeliminar al examen de los citados principios recogidos en el artículo 55.2 del EBEP, entendemos que es preciso determinar el origen axiológico constitucional de estos principios, y este no es otro que las previsiones constitucionales recogidas en el artículo 103.1, de manera, que se constituyen en una manifestación del Principio de Objetividad ${ }^{10}$, ya que este se configura en una pieza clave en la configuración del régimen del empleo público, en su totalidad, siendo su ámbito y el régimen jurídico del acceso y la selección al mismo, una de sus manifestaciones, ya que, este principio se proyecta sobre la exigencia de la existencia de una serie de garantías en el acceso al empleo público, de forma que este se realice con absoluto respeto a los principios de igualdad, mérito y capacidad, y así garantizar la neutralidad política de la administración pública, entendida esta como exigencia directa de la Constitución Española.

Pues bien, determinado el fundamento axiológico, procede examinar el primero de los principios, en concreto, la exigencia de «imparcialidad», debemos recordar como el Tribunal Constitucional ${ }^{11}$, ha señalado que esta presenta un contenido subjetivo, entendido este como la prohibición de intervención a aquellos miembros que hayan tenido una relación previa indebida o inconveniente, y por otro lado, un contenido objetivo, que al igual que en el caso anterior impide la participación pero por causa de la existencia de vínculos directos y permanentes con los ciudadanos que optan al proceso selectivo, así, no puede negarse que las organizaciones sindicales están formadas no solo por emplea-

\footnotetext{
10 FondeVila Antolín, J. (2000), «Constitución y Empleo Público», Comares-Granada, págs. 133 y ss.

11 Los pronunciamientos del Tribunal Constitucional son referidos especialmente al ámbito judicial, si bien, sus consideraciones son de directa aplicación a nuestro caso, así destacan SsTC 5/2004, 240/2005, 306/2005 y 55/2007).
} 
dos públicos, sino por un amplio conjunto de ciudadanos pertenecientes gremialmente a la organización, teniendo estas establecido en sus propios Estatutos lógicamente la defensa de sus afiliados, lo que supone que difícilmente se pueda afirmar que se dan las condiciones para hablar de imparcialidad, ya que no hay duda de la existencia de vínculos directos y permanentes .

A lo anterior, también le resultan de aplicación otras previsiones recogidas por normas vigentes con anterioridad a la entrada en vigor del EBEP, pero que entendemos no han resultado afectadas, en el sentido de su derogación expresa o tácita, nos referimos, en concreto, a las previsiones de los artículos 28 y 29 de la Ley 30/1992 LRJPAC que regulan las causas legales de abstención y recusación.

Por último, no hay que olvidar cual es la razón que ha animado al legislador ha incorporar la exigencia como principio básico la imparcialidad, y que no es otra, como ya manifestó la Comisión de Expertos y también hemos expuesto nosotros anteriormente, que la confirmación de que nuestro sistema de selección se ha visto afectado en demasiadas ocasiones por el clientelismo social y político, y estas previsiones más las que analizaremos a continuación, se han diseñado con la única finalidad de evitar, en la medida de lo posible, el lastre que presenta nuestro sistema en estos momentos.

En cuanto, a la profesionalidad esta debe ser entendida como la obligación de que «todos» los miembros, sin excepción, estén en posesión de los conocimientos necesarios en las materias sobre las que versa el proceso selectivo, es decir, nos estamos refiriendo al denominado por la doctrina y jurisprudencia ${ }^{12}$ como principio de especialización, por ello, debemos felicitarnos por la incorporación al texto del Estatuto Básico de una exigencia que hasta el sentido común demandaba, aunque los órganos políticos encargados de nombrar a los miembros de los Tribunales, tuvieran una tendencia, realmente inexplicable, a incumplirlo, nombrando como miembros de los órganos de selección a representantes políticos o sindicales designados directamente por sus organizaciones con independencia de que cumplieran el requisito esencial de estar en posesión de la cualificación profesional necesaria para poder calificar un ejercicio del proceso selectivo.

12 Alegre Ávila, J. M., (1992): «Objetividad e imparcialidad de la Administración. El principio de especialidad en la composición de los órganos de selección», Revista Vasca de Administración Pública 34, págs. 9 y ss., este precursor artículo partiendo de la constatación de que la Constitución Italiana reconoce unos principios de organización administrativa coincidentes con nuestro orden constitucional, en concreto, objetividad, imparcialidad y eficacia, llama la atención sobre el pronunciamiento de la «Corte Constituzionale», en su sentencia $n .^{\circ} 453 / 1990$, que anula una Ley regional, por entender que no se respetaba el principio de imparcialidad, en las comisiones de selección la no exigirse que al menos la mayoría de sus miembros tuvieran una especialización y cualificación adecuada para la valoración que debían realizar, de ahí que justifique la reclamación del mismo criterio para nuestro ordenamiento jurídico, al amparo de las previsiones de los artículos 103.3 y 23.2 de la Constitución Española; y también destacar la reciente Sentencia del TS de 5 de marzo de 2007 , referida específicamente al ámbito local, pero cuyas conclusiones pueden ser aplicadas con carácter general. 
Por último, con relación al Principio de Independencia, hay que entender el mismo, como ya ha señalado la doctrina ${ }^{13}$, en el sentido que los órganos de selección no pueden estar sujetos a instrucciones de ningún tipo, ni a interferencias o influencias espurias por parte de persona u organización alguna.

Así pues, la obligada aplicación de estos principios conectados directamente con el orden axiológico constitucional derivado de las previsiones del artículo 103.1 de la Constitución Española (Principio de Objetividad), supone que cualquier decisión que se adopte reconociendo la incorporación o participación de organizaciones sindicales en los órganos de selección de las administraciones públicas colisionaría directamente con el orden interno de principios (artículo 55) que ordena sistemáticamente todo el Capitulo I del Título IV del EBEP.

\section{EXAMEN DEL DERECHO DE LIBERTAD SINDICAL: ¿HAY COLISIÓN ENTRE ESTE DERECHO Y LA DECISIÓN LEGAL DE EXCLUSIÓN DE LAS ORGANIZACIONES SINDICALES, ASOCIACIONES PROFESIONALES Y DEMÁS ÓRGANOS DE REPRESENTACIÓN DE LOS ÓRGANOS DE SELECCIÓN?}

Tras comprobar que la decisión de excluir a las organizaciones sindicales de los órganos de selección, cuenta con el amparo de una serie de principios que cuentan con el reconocimiento expreso de la Ley, y que provienen de las exigencias del propio orden axiológico constitucional, tal como destacó PAREJO AlFONSO ${ }^{14}$, en cuánto a la configuración de la Administración Pública como proyección del Estado Social y de Derecho, lo que, a nuestro juicio, supone que la decisión del legislador ordinario sobre las previsiones del artículo 60, no solo cuenta con amparo constitucional sino que son exigencia directa de ese mismo orden normativo, entendemos que ahora es preciso comprobar si pudiera existir alguna clase de colisión con el ejercicio de la libertad sindical como organizaciones y también de los derechos de los órganos unitarios de representación.

\section{A) Análisis de la configuración del Derecho de Libertad Sindical en el orden constitucional español}

La Constitución Española regula de forma detallada este derecho a través de las previsiones de los artículos 7 y $28.1^{15}$ de la Constitución Española, habién-

\footnotetext{
13 SÁncheZ Morón, M. (2007), «Comentarios al Estatuto Básico del Empleado Público», Lex Nova-Valladolid, pág. 399.

14 PARejo Alfonso, L. (1983). «Estado Social y Administración Pública (Los postulados Constitucionales de la Reforma Administrativa)», Civitas, Madrid, págs. 29 y ss.

15 Artículo 7.
} 
dose realizado el desarrollo de este derecho fundamental por medio de la Ley 11/1985 de 2 de agosto, Orgánica de Libertad Sindical, siendo este, en principio, el marco jurídico esencial al objeto de delimitar el alcance jurídico material de este derecho fundamental.

Así, se ha expuesto por la doctrina laboral ${ }^{16}$, que en la configuración de este derecho se puede hablar de un contenido individual y otro colectivo, el primero de ellos respondería al conjunto de derechos de los que serían titulares los trabajadores individualmente considerados (artículo 28.1 CE), y en cuánto, a su ámbito colectivo nos encontraríamos ante los derechos que les correspondería a los sindicatos constituidos (artículo 7 y $28.1 \mathrm{CE}$ ).

Ahora bien, nos parece más clarificadora para el objetivo de este trabajo, la clasificación de ALBIOL ${ }^{17}$, así, se puede afirmar que existe un contenido esencial de la libertad sindical, directamente derivado de las previsiones de los artículos 7 y 28.1 de la CE, si bien, ese contenido no puede ser considerado como un listado cerrado y completo según indica el Tribunal Constitucional, en su STC 23/1983, que señala:

«...por muy detallado y concreto que parezca el artículo 28.1 CE a propósito del contenido de la libertad sindical, no puede considerársele como exhaustivo o limitativo sino meramente ejemplificativo, con la consecuencia de que la enumeración expresa de los derechos concretos que integran el genérico de la libertad sindical no agota, en absoluto, el contenido global o total de dicha libertad.»

Por ello, este marco normativo para la delimitación de la libertad sindical, debe ser ampliado, tal como ha reconocido el propio Tribunal Constitucional, en sus SsTC 78/1982 y 84/1989, en primer lugar, de conformidad con las previsiones del artículo 10.2 de la Constitución Española que se remite a los Tratados y acuerdos internacionales ratificados por España, así completarían el

Los sindicatos de trabajadores y las asociaciones empresariales contribuyen a la defensa y promoción de los intereses económicos y sociales que les son propios. Su creación y el ejercicio de su actividad son libres dentro del respeto a la Constitución y a la ley. Su estructura interna y funcionamiento deberán ser democráticos.

Artículo 28

1. Todos tienen derecho a sindicarse libremente. La ley podrá limitar o exceptuar el ejercicio de este derecho a las Fuerzas o Institutos armados o a los demás Cuerpos sometidos a disciplina militar y regulará las peculiaridades de su ejercicio para los funcionarios públicos. La libertad sindical comprende el derecho a fundar sindicatos y a afiliarse al de su elección, así como el derecho de los sindicatos a formar confederaciones y a fundar organizaciones sindicales internacionales o a afiliarse a las mismas. Nadie podrá ser obligado a afiliarse a un sindicato.

16 Palomeque López, M.C., coautor con Álvarez De la Rosa, M., (2005), «Derecho del Trabajo», Editorial Ramón Areces, Madrid, págs. 311 y ss.; para una exposición complementaria ALONSO OLEA, M. y CAsas BaAmonde, M. E. (2002), «Derecho del Trabajo», Civitas, Madrid, págs. 613 y ss. y por último, Rodríguez PIÑERo, M. (1986) - Coordinador-, «Comentarios a la Ley Orgánica de Libertad Sindical», Tecno-Madrid.

17 Albiol Montesinos, I., coautor junto a SAla Franco, T., (2003), «Derecho Sindical», Tirant lo Blanch (9. ${ }^{\circ}$ Edic.)-Valencia, pág. 44. 
ámbito material del derecho de libertad sindical, fundamentalmente, los Convenios 87 y 98 de la OIT, a lo que habría que añadir otros instrumentos internacionales, como ha declarado el Tribunal Constitucional (STC 23 noviembre de 1981), que señala expresamente:

«...las recomendaciones de la OIT, si bien como es obvio, distintas de los Convenios y sin alusión directa en el artículo 10.2 CE, son textos orientativos que sin eficacia vinculante pueden operar como criterios interpretativos o aclaratorios de los Convenios.»

Y en segundo lugar, serán las leyes que desarrollen las previsiones constitucionales que las complementen el contenido de este derecho, de forma que se amplíen las facultades y derechos reconocidos a las organizaciones sindicales, incorporándose los mismos al núcleo esencial del derecho analizado, en este sentido destacan las SsTC 9/1988, 39/1986, 51/1988, entre otras.

Como consecuencia de lo anteriormente expuesto, se puede afirmar que existe un «contenido esencial yotro adicional del derecho de libertad sindical» ${ }^{18}$, debiendo entender que en relación al primero de estos:

a) El contenido esencial supone no solo el derecho de constituir sindicatos y el de afiliarse a los mismos, sino también que las organizaciones sindicales realicen las funciones que de ellos es deseable esperar, dentro del Estado Democrático Constitucional ${ }^{19}$, constituyendo todo ello, el núcleo esencial del derecho.

Por ello, si se analiza de forma coordinada las previsiones de los artículos 7 y 28.1, a las organizaciones sindicales les corresponde «el ejercicio de aquellos derechos necesarios para el cumplimiento de tal función y que constituyen manifestación ineludible de la libertad sindical reconocida en el artículo 28.1 en su vertiente colectiva» (SsTC 45/1984 y 39/1986).

Así, entiende AlBIOL $^{20}$, que estos derechos necesarios a incluir en el contenido del derecho de libertad sindical, son los siguientes: negociación colectiva, huelga e incoación de conflictos (SsTC 39/1986 y 9/1988).

b) A ese ámbito esencial del derecho debe añadirse un contenido adicional, así reconocido por el Tribunal Constitucional en su STC 9/1988, de forma que el derecho de libertad sindical quedaría integrado por los derechos o facultades básicas que el ordenamiento jurídico les reconocería, lo que por otro lado no impide que los mismos puedan ser objeto de modificación o incluso supresión (SsTC 9/1988 y 61/1989).

\footnotetext{
18 Albiol Montesinos, I. (2003), págs. 45 y ss.

19 STC 70/1982.

20 Albiol Montesinos, I. (2003), pág. 45.
} 
Y alcanzado este punto del análisis, resulta necesario incidir para una correcta ubicación de la cuestión objeto de este trabajo, en el contraste entre lo expuesto y la cuestión de la participación de los sindicatos en los «órganos de selección», así tras haber examinado el denominado «contenido esencial» del derecho de libertad sindical, no es posible reconducir a su ámbito la existencia de un derecho constitucional de participación en los mismos, por ello, podemos afirmar, a nuestro juicio, que este derecho de participación fue reconocido hasta este momento por medio de diversos instrumentos normativos (RD 364/1995 y los correspondientes Convenios Colectivos aplicables en cada una de las Administraciones Públicas), todos ellos, de rango jerárquico inferior a la Ley, y por lo tanto susceptibles de modificación o supresión sin colisión legal alguna con el orden constitucional.

Por ello, tiene amparo legal y constitucional la decisión emanada de las previsiones del artículo 60.3 del EBEP, por cuánto además este en su artículo 1.2 declara que el objeto del mismo es la regulación de las normas aplicables al personal laboral al servicio de las Administraciones Públicas, a lo que se debe añadir la precisión efectuada por el legislador en el Capitulo I del Título IV (Acceso al empleo público y adquisición de la relación de empleo), cuándo el artículo 55.2 declara la aplicación del contenido del citado capitulo tanto al personal funcionario como laboral al servicio de las administraciones públicas, y ello, con independencia de las previsiones del artículo 61.7 del EBEP, que será objeto de un examen detallado posteriormente.

\section{B) Examen del régimen de participación de los órganos unitarios de representación del Personal al servicio de las Administraciones Públicas (Juntas de Personal y Comités de Empresa)}

En relación a las denominadas «Juntas de Personal», órganos de representación específicos para el personal con relación jurídico funcionarial, debemos remitirnos directamente a las propias previsiones del EBEP, en concreto, las previsiones del artículo $40^{21}$ del citado cuerpo legal, y tras un examen detallado

21 Artículo 40. Funciones y legitimación de los órganos de representación.

1. Las Juntas de Personal y los Delegados de Personal, en su caso, tendrán las siguientes funciones, en sus respectivos ámbitos:

a. Recibir información, sobre la política de personal, así como sobre los datos referentes a la evolución de las retribuciones, evolución probable del empleo en el ámbito correspondiente y programas de mejora del rendimiento.

b. Emitir informe, a solicitud de la Administración Pública correspondiente, sobre el traslado total o parcial de las instalaciones e implantación o revisión de sus sistemas de organización y métodos de trabajo.

c. Ser informados de todas las sanciones impuestas por faltas muy graves.

d. Tener conocimiento y ser oídos en el establecimiento de la jornada laboral y horario de trabajo, así como en el régimen de vacaciones y permisos. 
del mismo se puede afirmar, sin duda alguna, que estas no ostentan competencia o derecho alguno con respecto a esta cuestión, con lo cual no puede alegarse en ningún momento que estemos en presencia de un contenido adicional a la libertad sindical constitucionalmente reconocida a las organizaciones sindicales.

\author{
Por otro lado, nos encontramos con la figura de los Comités de Empresa, \\ cuyas competencias se encuentran reguladas básicamente en el artículo $64^{22} \mathrm{del}$
}

e. Vigilar el cumplimiento de las normas vigentes en materia de condiciones de trabajo, prevención de riesgos laborales, Seguridad Social y empleo y ejercer, en su caso, las acciones legales oportunas ante los organismos competentes.

f. Colaborar con la Administración correspondiente para conseguir el establecimiento de cuantas medidas procuren el mantenimiento e incremento de la productividad.

2. Las Juntas de Personal, colegiadamente, por decisión mayoritaria de sus miembros y, en su caso, los Delegados de Personal, mancomunadamente, estarán legitimados para iniciar, como interesados, los correspondientes procedimientos administrativos y ejercitar las acciones en vía administrativa o judicial en todo lo relativo al ámbito de sus funciones.

22 «Artículo 64. Derechos de información y consulta y competencias.

1. El comité de empresa tendrá derecho a ser informado y consultado por el empresario sobre aquellas cuestiones que puedan afectar a los trabajadores, así como sobre la situación de la empresa y la evolución del empleo en la misma, en los términos previstos en este artículo.

Se entiende por información la transmisión de datos por el empresario al comité de empresa, a fin de que éste tenga conocimiento de una cuestión determinada y pueda proceder a su examen. Por consulta se entiende el intercambio de opiniones y la apertura de un diálogo entre el empresario y el comité de empresa sobre una cuestión determinada, incluyendo, en su caso, la emisión de informe previo por parte del mismo.

En la definición o aplicación de los procedimientos de información y consulta, el empresario y el comité de empresa actuarán con espíritu de cooperación, en cumplimiento de sus derechos y obligaciones recíprocas, teniendo en cuenta tanto los intereses de la empresa como los de los trabajadores.

2. El comité de empresa tendrá derecho a ser informado trimestralmente:

a) Sobre la evolución general del sector económico a que pertenece la empresa.

b) Sobre la situación económica de la empresa y la evolución reciente y probable de sus actividades, incluidas las actuaciones medioambientales que tengan repercusión directa en el empleo, así como sobre la producción y ventas, incluido el programa de producción.

c) Sobre las previsiones del empresario de celebración de nuevos contratos, con indicación del número de éstos y de las modalidades y tipos que serán utilizados, incluidos los contratos a tiempo parcial, la realización de horas complementarias por los trabajadores contratados a tiempo parcial y de los supuestos de subcontratación.

d) De las estadísticas sobre el índice de absentismo y las causas, los accidentes de trabajo y enfermedades profesionales y sus consecuencias, los índices de siniestralidad, los estudios periódicos o especiales del medio ambiente laboral y los mecanismos de prevención que se utilicen.

3. También tendrá derecho a recibir información, al menos anualmente, relativa a la aplicación en la empresa del derecho de igualdad de trato y de oportunidades entre mujeres y hombres, entre la que se incluirán datos sobre la proporción de mujeres y hombres en los diferentes niveles profesionales, así como, en su caso, sobre las medidas que se hubieran adoptado para fomentar la igualdad entre mujeres y hombres en la empresa y, de haberse establecido un plan de igualdad, sobre la aplicación del mismo.

4. El comité de empresa, con la periodicidad que proceda en cada caso, tendrá derecho a:

a) Conocer el balance, la cuenta de resultados, la memoria y, en el caso de que la empresa, prevista la forma de sociedad por acciones o participaciones, los demás documentos que se den a conocer a los socios, y en las mismas condiciones que a éstos. 
REALA 306 (ENERO-ABRIL, 2008)

b) Conocer los modelos de contrato de trabajo escrito que se utilicen en la empresa así como los documentos relativos a la terminación de la relación laboral.

c) Ser informado de todas las sanciones impuestas por faltas muy graves.

Asimismo, el comité de empresa tendrá derecho a recibir la copia básica de los contratos y la notificación de las prórrogas y de las denuncias correspondientes a los mismos en el plazo de diez días siguientes a que tuvieran lugar.

5. El comité de empresa tendrá derecho a ser informado y consultado sobre la situación y estructura del empleo en la empresa o en el centro de trabajo, así como a ser informado trimestralmente sobre la evolución probable del mismo, incluyendo la consulta cuando se prevean cambios al respecto.

Asimismo, tendrá derecho a ser informado y consultado sobre todas las decisiones de la empresa que pudieran provocar cambios relevantes en cuanto a la organización del trabajo y a los contratos de trabajo en la empresa. Igualmente tendrá derecho a ser informado y consultado sobre la adopción de eventuales medidas preventivas, especialmente en caso de riesgo para el empleo.

El comité de empresa tendrá derecho a emitir informe, con carácter previo a la ejecución por parte del empresario de las decisiones adoptadas por éste, sobre las siguientes cuestiones:

a) Las reestructuraciones de plantilla y ceses totales o parciales, definitivos o temporales, de aquélla.

b) Las reducciones de jornada.

c) El traslado total o parcial de las instalaciones.

d) Los procesos de fusión, absorción o modificación del estatus jurídico de la empresa que impliquen cualquier incidencia que pueda afectar al volumen de empleo.

e) Los planes de formación profesional en la empresa.

f) La implantación y revisión de sistemas de organización y control del trabajo, estudios de tiempos, establecimiento de sistemas de primas e incentivos y valoración de puestos de trabajo.

6. La información se deberá facilitar por el empresario al comité de empresa, sin perjuicio de lo establecido específicamente en cada caso, en un momento, de una manera y con un contenido apropiados, que permitan a los representantes de los trabajadores proceder a su examen adecuado y preparar, en su caso, la consulta y el informe.

La consulta deberá realizarse, salvo que expresamente esté establecida otra cosa, en un momento y con un contenido apropiados, en el nivel de dirección y representación correspondiente de la empresa, y de tal manera que permita a los representantes de los trabajadores, sobre la base de la información recibida, reunirse con el empresario, obtener una respuesta justificada a su eventual informe y poder contrastar sus puntos de vista u opiniones con objeto, en su caso, de poder llegar a un acuerdo sobre las cuestiones indicadas en el apartado 4, y ello sin perjuicio de las facultades que se reconocen al empresario al respecto en relación con cada una de dichas cuestiones. En todo caso, la consulta deberá permitir que el criterio del comité pueda ser conocido por el empresario a la hora de adoptar o de ejecutar las decisiones.

Los informes que deba emitir el comité de empresa deberán elaborarse en el plazo máximo de quince días desde que hayan sido solicitados y remitidas las informaciones correspondientes.

7. El comité de empresa tendrá también las siguientes competencias:

a) Ejercer una labor:

1. De vigilancia en el cumplimiento de las normas vigentes en materia laboral, de seguridad social y de empleo, así como del resto de los pactos, condiciones y usos de empresa en vigor, formulando, en su caso, las acciones legales oportunas ante el empresario y los organismos o tribunales competentes.

2. De vigilancia y control de las condiciones de seguridad y salud en el desarrollo del trabajo en la empresa, con las particularidades previstas en este orden por el artículo 19 de esta Ley.

3. ${ }^{\circ}$ De vigilancia del respeto y aplicación del principio de igualdad de trato y de oportunidades entre mujeres y hombres.

b) Participar, como se determine por convenio colectivo, en la gestión de obras sociales establecidas en la empresa en beneficio de los trabajadores o de sus familiares. 
RDL 1/1995, del Estatuto de los Trabajadores, tras su última modificación operada por la Ley 38/2007, de 16 de noviembre, el cual tras proceder del mismo modo que en el caso anterior y examinar la doctrina laboral al respecto ${ }^{23}$, nos lleva a la conclusión que, en ningún caso existe reconocimiento legal alguno a la participación en los órganos de selección en las administraciones públicas y menos aún en el ámbito de la empresa privada.

Por lo tanto, en este caso tampoco existe colisión alguna entre el ordenamiento básico constitucional sobre el derecho de libertad sindical, y la declaración del artículo 60.3 del EBEP, y su determinación de la exclusión de los representantes de las organizaciones sindicales en los órganos de selección, por lo que debemos concluir que la pregunta que inicialmente formulábamos queda resuelta de una forma absolutamente favorable a las previsiones del EBEP, no siendo posible la utilización del argumento de una posible violación de este derecho de libertad sindical como justificación para reclamar la participación en los citados órganos.

\section{EXAMEN DEL ARTÍCULO 60.3 DEL EBEP, EN CONCRETO, SU PREVISIÓN DE EXCLUSIÓN DE LAS ORGANIZACIONES SINDICALES, ASOCIACIONES PROFESIONALES Y DEMÁS ÓRGANOS DE REPRESENTACIÓN DE LOS ÓRGANOS DE SELECCIÓN}

El texto del precepto, objeto final de este trabajo, señala que la participación en los órganos de selección deberá ser siempre a título individual, no siendo admisible actuar en representación o por cuenta de nadie.

c) Colaborar con la dirección de la empresa para conseguir el establecimiento de cuantas medidas procuren el mantenimiento y el incremento de la productividad, así como la sostenibilidad ambiental de la empresa, si así está pactado en los convenios colectivos.

d) Colaborar con la dirección de la empresa en el establecimiento y puesta en marcha de medidas de conciliación.

e) Informar a sus representados en todos los temas y cuestiones señalados en este artículo en cuanto directa $\mathrm{o}$ indirectamente tengan o puedan tener repercusión en las relaciones laborales.

8. Lo dispuesto en el presente artículo se entenderá sin perjuicio de las disposiciones específicas previstas en otros artículos de esta Ley o en otras normas legales o reglamentarias.

9. Respetando lo establecido legal o reglamentariamente, en los convenios colectivos se podrán establecer disposiciones específicas relativas al contenido y a las modalidades de ejercicio de los derechos de información y consulta previstos en este artículo, así como al nivel de representación más adecuado para ejercerlos».

23 Galiana Moreno, J. (2005), en AAVV. «Comentarios al Estatuto de los Trabajadores», Aranzadi, Pamplona , págs. 561 y ss., asimismo, ALBIOL MonTESINOS, I. (2003), págs. 202 y ss., y para un examen más amplio de la cuestión es muy recomendable la obra SEMPERE NAVARRO, A. V., (coordinación), de AAVV (2007) «Gobierno de la Empresa y participación de los Trabajadores: Viejas y nuevas formas institucionales ( XVII Congreso Nacional de Derecho del Trabajo y de la Seguridad Social)», Ministerio de Trabajo y Asuntos Sociales, Madrid, y por último, con re3ferencia al ámbito de influencia de la normativa europea al respecto y en especial la cuestión del Comité de Empresa Europeo, DurÁn LóPEZ, F. y SAÉz LARA, C. (1997), «El Papel de la participación en las nuevas Relaciones Laborales», Civitas, Madrid. 
Lo primero que debemos destacar con relación al precepto, es que sus previsiones resultan de directa aplicación, tanto al personal funcionario como laboral, es decir, no existe ámbito de exclusión, tal como ya hemos explicado anteriormente, y junto con esta consideración, también debe tenerse en cuenta que deberá entenderse derogada tácitamente, cualquier legislación o convenio colectivo que contradiga las previsiones de este precepto en su integridad y no solo este último apartado, cuestión esta, sobre la que volveremos posteriormente con mayor detalle.

Ahora bien, es cierto que desde la propuesta inicial de la Comisión de Expertos, y el texto articulado inicial, la redacción de este artículo del EBEP, ha sufrido varios cambios, en un intento sobre todo de las organizaciones sindicales, asociaciones profesionales y órganos legales de representación, de no perder esa cuota de poder y clientelismo social que les daba su participación en los órganos de selección, de todas formas esa propuesta y lo aprobado definitivamente no es sino una continuación de las previsiones del apartado segundo de este mismo artículo, con referencia a los cargos políticos.

Es cierto que las diferentes negociaciones desarrolladas en torno al Proyecto de Ley, especialmente la realizada en el seno de la Comisión de Administraciones Públicas del Congreso de los Diputados, que origino que en su Dictamen se eliminara la mención expresa a las organizaciones sindicales, pero eso no significa que no quedaran excluidas esta clase de organizaciones, en este sentido ya se han manifestado varios de los miembros de la Comisión de Expertos ${ }^{24}$, e igualmente debemos tener en cuenta el proceso final de aprobación del texto legal, así, con relación a la fase de enmiendas al artículo 60 realizada en el Senado, debemos destacar especialmente la enmienda del Bloque Nacionalista Galego $^{25}$ (GPMX ), en concreto con carácter de adición, por la cual se solicitaba la incorporación de un nuevo apartado cuarto al artículo 60, cuyo contenido era el siguiente:

«4. Las organizaciones sindicales tendrán derecho a recibir información y a efectuar un seguimiento de los procesos de selección.»

Efectivamente, el sentido de esta enmienda aclara perfectamente, cual es el contenido material de la actual redacción del precepto, ya que precisamente la constancia de que el mismo supone la exclusión radical de las organizaciones sindicales justifica el intento de la enmienda de otorgar, al menos, a estas un derecho de información y seguimiento de los procesos ante la imposibilidad de

\footnotetext{
24 Efectivamente tanto OrTEga ÁlvareZ, L. como SÁnCHEZ Morón, M., manifestaron expresamente que la denominada «cuota sindical» en los Tribunales de selección debía considerarse definitivamente excluida a la vista de las previsiones de este precepto, estas declaraciones se realizaron en la Universidad Internacional Menéndez Pelayo ( UIMP), en Santander, dentro del Curso denominado: «El desarrollo del Estatuto Básico del Empleado Público», organizado por el MAP y celebrado los días 3 al 7 de septiembre de 2007.

25 Enmienda n. ${ }^{\circ} 7$ de Adicción del BNG, publicada en el BOCG del Senado Serie II n. ${ }^{\circ} 85$ (d) de 21 de febrero de 2007.
} 
formar parte de los órganos de selección, por lo cual, debemos ratificar desde la denominada «ratio legis», que no hay duda de la exclusión de estas organizaciones.

A esto, debemos reiterar lo comentado al inicio de este trabajo, con relación al carácter «compensatorio» por la pérdida sufrida por las organizaciones sindicales en su cuota de poder selectivo, que supone la incorporación de las previsiones del artículo 31.6 del EBEP y el reconocimiento de legitimación activa para accionar contra las resoluciones en los procesos selectivos, única y exclusivamente para el ámbito sindical, a las organizaciones sindicales más representativas en el ámbito de la función pública, es decir, solo lo tienen CCOO, CSI-CSIF y UGT, curiosamente las tres organizaciones que dieron su conformidad al Proyecto de Ley presentado por el Gobierno del Estado.

Por último, no por obvio, entendemos que no debamos realizar una mención a los propios conceptos de «representación o por cuenta», efectivamente nos encontramos ante instrumentos jurídicos de amplio arraigo en nuestro ordenamiento jurídico privado, es decir, nuestro Código Civil, y a ello, debemos añadir que estos también han sido objeto de una amplio estudio por parte de la doctrina civilista ${ }^{26}$, la cual claramente diferencia entre la llamada «representación indirecta», que supone que el representante realiza el acto en nombre propio, aunque por cuenta de otro, y por otro lado, tenemos la llamada «representación directa», en la cual el representante realiza el acto a nombre del representado, pues bien, no existe duda de que las previsiones del apartado tercero del artículo 60, comprende de modo expreso ambos tipos de representación, dicho lo cual, debemos partir de una primera consideración básica, que los nombramientos de miembros de órganos de selección, siempre se realizaban en respuesta a una cuota reservada a estas organizaciones, las cuales designaban las personas que les iban a representar como organización y dentro de su cuota, con independencia de si su actuación respondía más a una representación indirecta o directa, por lo cual no existe duda de que se cumplen los notas básicas reconocidas tanto por la doctrina civilista como por nuestro propio ordenamiento jurídico, para afirmar que estamos en presencia de un proceso de otorgamiento de representación, lo cual, se encuentra de modo expreso prohibido por el precepto analizado del EBEP.

Es cierto, que ante este panorama se intenta seguir nombrando a representantes de las organizaciones sindicales, pero de forma encubierta, es decir, respetando de «facto», la cuota pactada, si bien, «formalmente», el nombramiento se hace a título individual, entendemos que estamos en presencia de un «fraude legis», que con un examen detallado de las convocatorias y las adscripciones sindicales de algunos de los miembros de los órganos de selección, en vía juris-

26 Castán Tobeñas, J., (2005) «Derecho Civil Español Común y Foral» Tomo I-Vol. I, págs. 592 y ss., también EsPín CÁNOVAS, D. (1978), «Manual de Derecho Civil Español» Vol. I, págs. 451 y ss. 
diccional no sería excesivamente complicado conseguir la nulidad del nombramiento, y en especial, si estos recaen en personas con cargos en órganos de representación, institucionales (Mesas de negociación) u organizativos en su propio sindicato.

Pues bien, para un examen completo y sistemático de la cuestión, es preciso examinar ahora las previsiones del artículo 61.7 del EBEP, que es resultado igualmente de la citada negociación con las organizaciones sindicales, y cuyo contenido se hace, en principio, difícil de determinar, en concreto, nos referimos al acotamiento jurídico material de la facultad reconocida a las organizaciones sindicales para «negociar las formas de colaboración que en el marco de los convenios colectivos fijen la actuación de las organizaciones sindicales en el desarrollo de procesos selectivos».

Desde luego, conviene realizar unas reflexiones sobre el contenido del precepto:

a) Como ya indicamos anteriormente en este trabajo, el acceso al empleo público, y por ende, los procedimientos y procesos selectivos, forman parte del derecho individual de igualdad constitucionalmente reconocido a todos los ciudadanos de este país, por medio de las previsiones de los artículos 14, 23.2 y 103.3 de nuestra Carta Magna, por ello, no se alcanza a comprender cual es el papel que deben desempeñar unas entidades que representan unos concretos intereses profesionales, los de los empleados públicos ya incorporados a la administración, con la intervención en la determinación de las condiciones en que debe desarrollarse el ejercicio de un derecho fundamental de todos los ciudadanos (artículo 23.2 C.E.).

Ahora bien, estas consideraciones podrían resultar cuestionadas con relación al personal con relación jurídico laboral, si con la interpretación y puesta en marcha que se realice del artículo 61.7 del EBEP se pretenda vaciar de contenido las previsiones del artículo 60.3 del EBEP.

b) Por otro lado, no hay duda de que las previsiones de este apartado $7 .^{\circ}$, únicamente alcanzan al ámbito de las relaciones laborales y las organizaciones sindicales que desarrollen su actividad en ese sector, quedando expresamente fuera de su objeto los funcionarios y sus instrumentos de negociación (Acuerdos y Pactos), si bien, esta apreciación inicial, como veremos después, no resulta del todo cierta.

c) Una premisa esencial a tener en cuenta, es que las previsiones del artículo 60.3 del EBEP, se configuran como norma expresamente prohibitiva de carácter general y los efectos de su extensión alcanzan por razones constitucionales (naturaleza básica) a todas las administraciones públicas, y por razones subjetivas resulta de aplicación al conjunto de las relaciones de empleo público (funcionarios y laborales), por ello, este apartado séptimo del artículo 


\section{LA EXCLUSIÓN DE LA PARTICIPACIÓN DE LAS ORGANIZACIONES SINDICALES...}

61 no puede ser interpretado en colisión con las exigencias legales del precitado artículo, sino que el mismo debe ser integrado dentro del sentido general establecido de prohibición expresa de la participación sindical en los órganos de selección.

d) A la vista de lo expuesto, examinemos detalladamente el contenido del precepto, así, este establece que lo que se permite negociar son únicamente «formas de colaboración», lo que supone, a nuestro juicio, ${ }^{27}$ que en ningún caso estas pueden suponer una participación ni tan siquiera indirecta (en este sentido ya se ha planteado en algunos municipios la figura del observador), en los órganos de selección, dado que prevalece necesariamente el mandato general del artículo 60.3 de aplicación también al personal laboral.

Lógicamente debemos preguntarnos entonces cuál es el ámbito material donde se debe desarrollar esa colaboración, así, entendemos que debe acotarse el mismo, desde un criterio positivo, y por otro lado, a través de la vía de exclusión, así:

a) Empezando por el último de los criterios, como ha señalado Sánchez Morón ${ }^{28}$ esta colaboración no puede poner en cuestión, en ningún caso, el derecho a la igualdad de los ciudadanos en el acceso al empleo público, asimismo, como ya hemos indicado anteriormente, en ningún caso se pueden incumplir las previsiones del artículo 60.3 del EBEP.

b) Por otro lado, el EBEP ha modificado el régimen jurídico aplicable, sobre las materias que pueden ser objeto de negociación, pues recordemos que la Ley 9/1987 LORP, establecía en su artículo 32 g) la consideración de materia negociable «los sistemas de ingreso..... de los funcionarios públicos», no estableciendo el artículo 34 de la LORP ninguna excepción sobre esta materia como no objeto de negociación.

De forma, que ahora nos encontramos, con las previsiones del artículo 37.1 c) del EBEP que declara como materia objeto de negociación «las normas que fijen los criterios generales en materia de acceso....», como se puede comprobar con una simple lectura comparativa, las previsiones actuales son mucho más restrictivas que las anteriores, a nuestro juicio, la negociación queda limitada a la negociación de una futura Ley de función pública y su Reglamento de desarrollo, y en todo caso alguna Orden de naturaleza normativa ${ }^{29}$, pero resulta

\footnotetext{
27 En este mismo sentido se han pronunciado SÁNCHEZ MORÓN, M. (2007), págs. 413 y ss. y también ORTEGA ÁlVAREZ, L. en ponencia expuesta en la Universidad Internacional Menéndez Pelayo (UIMP), en Santander, dentro del Curso denominado: «El desarrollo del Estatuto Básico del Empleado Público», organizado por el MAP y celebrado los días 3 al 7 de septiembre de 2007.

28 SÁNCHEZ Morón, M. (2007), pág. 414.

29 Con relación a esta cuestión y en ese mismo sentido se ha manifestado RoQUETA BUJ, R., (2007), «El Derecho de Negociación Colectiva en el EBEP», Madrid-La Ley, pág 170.
} 
imposible descender más allá en la negociación, a diferencia de la anterior situación, y ello, por la previsión del artículo 37.2 e), que complementa las previsiones anteriores, al declarar de forma expresa la exclusión de la negociación de la «regulación y determinación concreta, en cada caso, de los sistemas, criterios, órganos y procedimientos de acceso al empleo público...», es decir, a simple título de ejemplo, las Bases de cualquier convocatoria quedarían excluidas de negociación sindical.

Ubicada la cuestión desde un punto de vista sistemático, y desde un criterio positivo procede realizar un examen más detallado sobre el alcance y aplicación de las previsiones del artículo 37.2 del EBEP, así, conforme manifiesta la doctrina $^{30}$, el mismo resulta de aplicación común a funcionarios y laborales, si bien, a nuestro juicio, esta afirmación no puede ser tan general, sino que es preciso colocar esa declaración en su correcta ubicación con relación a las previsiones del artículo 36. 2 y 3 del EBEP, en concreto, su declaración de que las materias recogidas en el artículo 37 del EBEP, serán objeto de negociación en los ámbitos de las diferentes Mesas de Negociación, siempre y cuándo afecten a materias «comunes» al personal funcionario y laboral, así, fijado el límite subjetivo de aplicación del artículo 37, se puede afirmar, a nuestro juicio, que la materia de selección que es común a ambos tipos de personal se encuentra por ello sometida a las previsiones del citado precepto, dicho esto, resulta imprescindible destacar que el artículo 37.2 del EBEP declara que quedan excluidas «de la obligatoriedad» de negociación, «la regulación y determinación concreta, en cada caso, de los sistemas, criterios, órganos y procedimientos de acceso al empleo público..», lo que a «sensu contrario», significa que es posible, si existe una decisión compartida entre los agentes negociadores (incluidos los funcionarios), incluir estas materias en los procesos de negociación, así pues, según nuestro criterio, este sería el posible espacio jurídico material que podría ser objeto de negociación y, como consecuencia de ello, dentro de este, establecer las denominadas medidas de colaboración, ahora bien, la experiencia de estos últimos 23 años, nos hace temer que podamos estar en presencia de una especie de «Caballo de Troya», con la finalidad de desactivar las novedades y mejoras que han introducido los artículos 55 y 60 del EBEP.

\section{CONSIDERACIONES FINALES}

La primera de las consideraciones que queremos realizar se centra en la aplicación de esta prohibición establecida en el EBEP, con relación al personal laboral, y con más precisión, la situación en la que quedan los Convenios Colectivos, vigentes en el momento de la entrada en vigor del EBEP, que en su articulado reconocían el derecho de participación sindical en los órganos de selección.

30 SÁnchez Morón, M. (2007), págs. 293 y ss. 
Así, es preciso repasar la jerarquía de fuentes aplicable, precisando la ubicación en el mismo de las previsiones de todo Convenio Colectivo, y así siguiendo la doctrina laboral ${ }^{31}$, podemos reseñar un orden básico de prelación de fuentes, con respeto a los principios de ordenación característicos del ordenamiento laboral, en concreto, principio de condición o norma mínima y el principio de condición o norma más favorable, así, el orden de fuentes resultante, de forma sintética, sería:

\section{La Constitución Española.}

2. Los Tratados Internacionales celebrados por el Estado y las Leyes: Orgánicas, Ordinarias y Delegantes, así como otras normas con rango de ley, en concreto, Decretos-Leyes y Decretos Legislativos.

3. Los Reglamentos y Órdenes Estatales.

4. Los Convenios Colectivos y las normas reglamentarias sectoriales, excepcionales y subsidiarias de aquellos, dictadas al amparo del estatuto de los Trabajadores (Disposición Adicional 7·a).

5. La Costumbre local y profesional.

A la vista de lo expuesto, resulta claro que los Convenios Colectivos ocupan una posición claramente supeditada e inferior a las previsiones que puedan emanar de las Leyes en su diferente configuración.

Por ello, como ha señalado algún sector de la doctrina laboral ${ }^{32}$, con independencia del reforzamiento que las últimas reformas legislativas han otorgado a la negociación colectiva, hay una conclusión que no admite discusión, y esta no es otra que la superioridad jerárquica de la fuente normativa estatal sobre la colectiva, por directa aplicación del principio de jerarquía normativa, conforme determina el artículo 9.3 de la C.E., en relación a los artículos 3 y 85.1 del Estatuto de los Trabajadores. Esto supone que «los mandatos de la Ley se imponen directa e inmediatamente al convenio, de manera que su contenido, presente o futuro, deberá acomodarse a lo establecido legalmente, so pena de nulidad»33.

Por lo tanto, a la vista de lo anteriormente expuesto, teniendo en cuenta además que no existe duda del título competencial del Estado para regular la materia, tanto por el carácter básico de las materias desarrolladas por el EBEP (103.3 y 149.1.18 C.E.), como por su competencia también exclusiva sobre el ordenamiento jurídico laboral (149.1.7 C.E.), tal como reconoce expresamente la Dis-

\footnotetext{
31 Alonso Olea, M y Casas BaAmonde, M. E. (2002), págs. 963 y ss.

32 CORREA CARRASCO, M., (1997), «Convenios y Acuerdos Colectivos de Trabajo», Aranzadi, Pamplona, págs. 244 y ss.

33 CORREA CARRASCO, M., (1997), pág. 246.
} 
posición Final primera del EBEP, no hay duda alguna que cualquier previsión que reconociera a las organizaciones sindicales u otro tipo de órganos representativos en los Convenios Colectivos, y que estuvieran vigentes en el momento de la entrada en vigor del EBEP, han quedado derogados, resultando por ello, sus disposiciones inaplicables.

Finalmente, queremos formular una segunda consideración, o más bien, propuesta de «lege ferenda», ya que nos encontramos ante una materia que debe ser desarrollada por las correspondientes Leyes que se deben elaborar para los ámbitos de la Administración General del Estado, cada una de las Comunidades Autónomas y la Administración Local, y la misma consiste en que entendemos que resultaría adecuado que en esos marcos normativos se procediera a regular con más detalle la exclusión de esta clase de organizaciones en los órganos de selección, de forma que quede cerrada definitivamente cualquier clase de polémica sobre este tema, ya que, si bien, a nuestro juicio, existen toda clase de razones absolutamente fundadas para sostener esta exclusión, es cierto, que la naturaleza conflictiva que conlleva siempre la toma de una decisión de estas características, supone que siempre van a aparecer subterfugios que intenten en «fraude legis», evitar el adecuado cumplimiento de las exigencias legales. 


\section{Crónicas y Documentos}

REALA-2008, núm. 306. JORGE FONDEVILA ANTOLÍN. LA EXCLUSIÓN DE LA PARTICIPACIÓN DE LAS ORGANIZACIONE... 